\title{
Article
}

\section{Low levels of salivary lactoferrin may affect oral dysbiosis and contribute to Alzheimer's disease: A hypothesis}

Olsen, Ingar and Singhrao, Simarjit Kaur

Available at http://clok.uclan.ac.uk/35464/

Olsen, Ingar and Singhrao, Simarjit Kaur ORCID: 0000-0001-9573-5963 (2020) Low levels of salivary lactoferrin may affect oral dysbiosis and contribute to Alzheimer's disease: A hypothesis. Medical hypotheses . ISSN 0306-9877

It is advisable to refer to the publisher's version if you intend to cite from the work. http://dx.doi.org/10.1016/j.mehy.2020.110393

For more information about UCLan's research in this area go to http://www.uclan.ac.uk/researchgroups/ and search for <name of research Group>.

For information about Research generally at UCLan please go to http://www.uclan.ac.uk/research/

All outputs in CLoK are protected by Intellectual Property Rights law, including Copyright law. Copyright, IPR and Moral Rights for the works on this site are retained by the individual authors and/or other copyright owners. Terms and conditions for use of this material are defined in the policies page.

\section{CLoK}

Central Lancashire online Knowledge www.clok.uclan.ac.uk

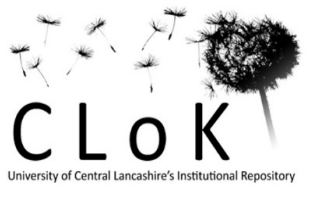


1

2 Low levels of salivary lactoferrin may affect oral dysbiosis

3

4

5

6

7

8

9

10

11

12

13 and contribute to Alzheimer's disease: A hypothesis

\author{
Ingar Olsen $^{1}$, Sim K. Singhrao ${ }^{2}$
}

Ingar Olsen

ingar.olsen@odont.uio.no

${ }^{1}$ Department of Oral Biology, Faculty of Dentistry, University of Oslo, Oslo, Norway

${ }^{2}$ Brain and Behavior Centre, Faculty of Clinical and Biomedical Sciences, School of Dentistry, University of Central Lancashire, Preston, UK

\section{ABSTRACT}

Recently it has been reported that reduced levels of salivary lactoferrin (LF) can be a plausible biomarker for amyloid beta $(\mathrm{A} \beta)$ accumulation as in the brain of Alzheimer's disease $(\mathrm{AD}) \underline{\text { brains. }}$. This could mean that reduced levels of salivary LF act as a trigger for oral dysbiosis and that low LF levels could change the oral microbiota. A chemical change in the composition of saliva has not yet been considered as a cause for microbial dysbiosis but does present an opportunity to view oral dysbiosis as a plausible contributory factor in the development of AD pathophysiology. Oral dysbiosis has largely been reported as a result of inadequate oral hygiene and dry mouth in elderly subjects. Here we discuss if the deficiency of LF in saliva and gingival fluid of AD patients can facilitate proliferation of oral pathogens, and as a result their spread elsewhere in the body. Additionally, we ask if LF in the AD brain could be overexposed as a result of chronic infection. Together these outcomes will indicate if reduced levels of salivary LF can act as a trigger of oral dysbiosis.

\section{Keywords:}

Lactoferrin 
Saliva

Brain

\section{Porphyromonas gingivalis}

Gingipains

Dysbiosis

\section{Introduction}

On the question of whether Alzheimer's disease (AD) is an infectious (communicable) disease the research of Olsen and Singhrao [1] and Singhrao and Harding [2] support the plausibility of $\mathrm{AD}$ being a polymicrobial dysbiosis of the host's microbiome.

Inadequate oral hygiene and dry mouth are accepted reasons for oral dysbiosis.

However, a change in the composition of saliva has not previously been considered as a cause for microbial dysbiosis. The reasons for dysbiosis in a host's oral microbiome could be due to unknown reasons whilst including those already linked to poor oral hygiene and xerostomia. Carro et al. [3], using mass spectrometry and ELISA, it was demonstratedshowed for the first time that early diagnosis of mild cognitive impairment (MCI) and subsequent AD can be associated with impairment of salivary lactoferrin (LF). Later, Gonzáles-Sánchez et al. [4] suggested that in salivary deficiency of LF, amyloid beta $(A \beta)$ could be a biomarker of $A D$ as it correlates with the $A \beta$ load in the brain following its visualization with amyloid-PositionEmission Tomography (PET) neuroimaging. We hypothesize that salivary LF deficiency may act as an unknown trigger of oral microbial dysbiosis. LF is a glycoprotein present in the human saliva. It is also found in secretions such as milk, tears and gingival fluid, and in cells like neutrophils [5] and has a broad spectrum antimicrobial activity. Being an antimicrobial peptide, LF is considered part of the first line or innate immune defense against infections in man [6] as it targets bacteria, viruses, fungi, yeasts and protozoa. LF is also an iron chelator and hence prevents iron deposition. It has the ability to block aggregation of both $A \beta$ and phosphorylated tau, and rescues neuronal damage in AD brains [7, 8]. For a summary of the biological functions of LF, see Table 1.

When $A \beta$ accumulation reaches a plateau possibly from both local and peripheral $A \beta$ pools [9], it indicates the MCI stage or prodromal AD. Following this stage, the pathological cascade of progressive AD takes over. As an antimicrobial peptide, LF can modulate immune reactions and inflammation (for a review see Farah et al. [10]). A plethora of reports 
implicate the immune system as a major player in AD manifestation [11-14]. There is probably an association between systemic infection and AD where salivary LF is downregulated like several other factors of systemic immunity [6].

The present paper will discuss (1) if deficiency of LF in saliva and gingival fluid of AD patients can facilitate proliferation of oral pathogens, (2) if this proliferation can result in transfer of oral pathogens and tissue inflammatory mediators to the brain, and (3) if LF in the brain of $\mathrm{AD}$ patients could be overexposed as a result of chronic infection.

\section{Decreased salivary lactoferrin is specific to Alzheimer's disease}

In a recent study Gonzáles-Sánchez et al. [4], who examined the relationship between salivary levels of LF and cerebral A $\beta$ load by using PET neuroimaging, found that LF could be used to detect MCI or prodromal $\mathrm{AD}$ and distinguish $\mathrm{AD}$ from other frontotemporal dementias (FTDs), with sensitivities and specificities over $87 \%$ and $91 \%$, respectively. This study also indicated that LF represents one of the main first lines of defense against pathogens and confirmed previous findings that there is an association between $\mathrm{AD}$ and the immune system, and brain infections with bacteria, viruses ander yeasts. These microorganisms can all be related to increased signs of neuroinflammation in the brain $[1,4,15]$. The study of Gonzáles-Sánchez et al. [4] was the first to show the diagnostic performance and specificity of a single saliva-based biomarker for detecting MCI and AD. It demonstrated that salivary LF levels are reduced in $\mathrm{AD}$ and, noteworthy, are associated with the amyloid-PET imaging profile, even in the prodromal stage. An independent cross-sectional study confirmed simultaneously the presence of low saliva LF levels in AD, as shown previously [3].

\section{Low salivary lactoferrin might be an effect of immunological disturbances in}

\section{Alzheimer's disease}

AD subjects have long been recognized to suffer from poor oral health and xerostomia which is thought to be a side effect of their medication. However, this view is changing as Bermeji-Pareija et al. [6] proposed that reduced levels of salivary LF might be an effect of immunological disturbances associated with AD. Two pathways could be responsible for this: first, AD could be a systemic disorder (or disorders) related to early immunological and low inflammatory changes, and secondly, systemic immunity changes in AD manifestation could 
be a downstream effect of early AD brain involvement. The authors emphasized that the general acceptance of low LF as an early AD biomarker would rely on validation of LF levels in other clinical and population-based studies.

Deficiency in salivary lactoferrin in Alzheimer's disease could contribute to dysbiosis of the oral microbiota

LF is secreted by the serous acinar cells of the major and minor salivary glands. In whole saliva it also originates from neutrophil granulocytes and from the gingival crevicular fluid. LF plays an important role in regulating the oral microbiota and the inflammatory state of the oral mucosa [16]. It contributes to the maintenance of symbiosis in the hostmicrobiome relationship. In dysbiosis, however, certain bacteria are able to flourish at the demise of others. Particularly the oral pathogen Porphyromonas gingivalis will take advantage of iron released from haem in inflamed tissues, and increase in number (Figure 1). This bacterium has a remarkable effect to initiate dysbiosis even in low concentration [17]. In dysbiosis, levels of salivary LF are expected to increase whilst the body resolves inflammation and restores symbiosis [18].

However, when LF levels are low, as seen in AD, dysbiosis is expected to proceed freely. In a study on the subgingival microbiota of people with cognitive dysfunction participants with periodontitis had a greater abundance of several bacteria: the highest $\log 2-$ fold changes were seen for Porphyromonas and Peptostreptococcaceae [19]. Even in aged subjects with oral dryness, salivary levels of LF and chromogranin A were low [20] and this may aid spread of oral bacteria to the brain.

Dysbiosis can also contribute to a dormant blood microbiome (atopobiosis) and directly promote systemic inflammation through amyloidogenic formation and shedding of inflammagens such as lipopolysaccharides (LPSs) [21]. Dormant, non-growing bacteria are important features in AD. Their growth in vivo is usually limited by a lack of free iron and this iron dysregulation could be an important factor in their resuscitation [22]. A simultaneous iron dysregulation and microbial aberrations could affect the hematological system by promoting fibrin amyloidogenesis and pathological clotting [23].

\section{Lactoferrin in the gingival crevicular fluid}


LF is part of the gingival crevicular fluid secreted from the inflamed periodontium around teeth harboring supra- and sub-gingival biofilms. Studies have shown that LF can be a biofilm inhibitor of periodontopathic bacteria in vitro and in vivo [24]. These authors reported that LF reduced the established biofilm at physiological concentrations. The adjunct use of LF for the prevention and treatment of periodontal diseases has therefore been suggested [25]. LF was raised in stimulated whole saliva in subjects with "chronic" periodontitis where it correlated with probing pocket depths $\geq 6 \mathrm{~mm}$ [26]. In a study by Daspher et al. [27], LF inhibited $P$. gingivalis biofilm formation by $80 \%$ at concentrations above $0.625 \mu \mathrm{M} . P$. gingivalis, which is a Gram-negative anaerobic rod, is considered a keystone bacterium in periodontitis [28-30]. The antimicrobial protection exerted by LF could be reduced when it is present in low concentrations, as in AD. Maintaining the flow of saliva and the presence of antimicrobial substances are important to preserve oral health. As mentioned, in the older population salivary flow is often reduced, for example as a side effect of drug intake. This could predispose these persons to systemic infection with periodontal bacteria.

\section{Periodontal bacteria can degrade lactoferrin by its proteases}

LF binds to a high-affinity receptor on periodontal bacteria such as $P$. gingivalis, Prevotella intermedia and Prevotella nigrescens. In the case of $P$. gingivalis, all strains completely degraded LF under the investigative conditions used, whereas only partial degradation was seen with P. intermedia and P. nigrescens [31]. The proteases (gingipains) of $P$. gingivalis may protect this bacterium against LF in periodontal and systemic sites and thus serve as important virulence factors. Alugupalli and Kalfas [32] found in an in vitro study that the degradation of LF was more extensive by $P$. gingivalis and Capnocytophaga sputigena, slow by Capnocytophaga ochracea, Aggregatibacter (Actinobacillus) actinomycetemcomitans and P. intermedia, and very slow or absent by P. nigrescens, Campylobacter rectus, Campylobacter sputorum, Fusobacterium nucleatum ssp. nucleatum, Capnocytophaga gingivalis, Tannerella (Bacteroides) forsythia and Peptostreptococcus micros. All the $P$. gingivalis strains tested degraded LF. The degradation was sensitive to the protease inhibitors cystatin $\mathrm{C}$ and albumin. These studies indicated that periodontopathogens can degrade LF. This could facilitate proliferation of some of the most virulent bacteria in periodontal infections, and possibly promote AD by systemic spread of these bacteria and their inflammagens to the brain. Inflammagens from $P$. gingivalis such as gingipain R1 
mechanics thereby driving systemic inflammation [33]. Interestingly, intake of tablets containing LF (60 mg/d) and lactoperoxidase $(7.8 \mathrm{mg} / \mathrm{d})$ improved gingival inflammation and oral health-related quality of life in healthy adults [34] supporting the concept that low levels of LF are indicators of dysbiosis.

\section{Porphyromonas gingivalis in Alzheimer's disease}

Recent work has increasingly focused on $\mathrm{AD}$ as a microbial disease, for example Sochocka et al. [15] and Itzaki et al. [35]. In the oral microbiota, $P$. gingivalis has attracted much attention for its possible role in AD (Figure 1) [13, 36-40]. However, it may take a long time for $P$. gingivalis to promote development of AD. Thus, Sparks Stein et al. [41], Tzeng et al. [42] and Chen et al. [43] found that gingivitis and chronic periodontal disease could take up to 10 years for $\mathrm{AD}$ to occur. This may also be the time it takes for $\mathrm{A} \beta$ to reach a plateau to become MCI.

\section{Low salivary lactoferrin could promote transfer of oral bacteria and tissue}

\section{inflammatory mediators to the brain}

Each time we chew on a periodontitis-affected tooth there will be a bacteremia. During a day this can last for a total of 3 hours [44]. The spectrum of oral bacteria in this bacteremia is wide [45] (Figure 1). Also viruses, bacteriophages and yeasts in the periodontal pocket could follow the bacteria into the blood stream as well as inflammatory mediators from the inflamed periodontal tissues [1]. In an elderly person with deteriorated blood-brain barrier, periodontal microorganisms and inflammatory mediators can reach the brain. Several other ways than the blood stream can also be used by oral microorganisms for brain transfer [1]. Periodontal pathogens like $P$. gingivalis and their main virulence factors, like LPS and gingipains have been demonstrated in the brain of $\mathrm{AD}$ patients and in animal models of $\mathrm{AD}$ [37, 46-48]. It is therefore highly plausible that low salivary LF levels, by reducing innate immunity, can promote dissemination of periodontitis-related microorganisms and inflammatory tissue mediators to the brain. In addition, salivary LF is transferred into the brain via the sublingual route [49]. Low levels of salivary LF may therefore affect the concentration of LF in the AD brain. 


\section{High concentrations of lactoferrin have initially a protective effect on Alzheimer's} disease

LF has been considered to have a beneficial effect in AD subjects, but the mechanism is unclear. A possible way could be through its ability to alleviate the AD pathological cascade and cognitive decline via modulation of the p-Akt/PTEN (phosphatidylinositol-4,5bisphosphate 3-kinase (PI3K)/protein kinase B (PKB or Akt)/phosphatase and tensin homolog (PTEN) pathway [50]. These authors reported a possible protective mechanism of post-LF administration for 3 months in AD patients' changes in this pathway. LF probably caused this by affecting key players of inflammation and oxidative stress involved in AD pathology. It should also be mentioned that iron dysregulation, which is seen in $\mathrm{AD}$, contributes to oxidative stress [21]. LF could reduce inflammation and stress by binding iron.

The spread of microorganisms to the brain is controlled by several factors, including LF which, as mentioned, also has an anti-inflammatory effect, especially associated with the down-regulation of pro-inflammatory cytokines like IL-6. This reduces local and/or systemic inflammation [51]. Excessive iron contributes to the deposition of $A \beta$ and the formation of neurofibrillary tangles, which in turn, promotes the development of AD [7]. LF blocks A $\beta$ aggregation, tauopathy spread and neuronal damage [7]. It also acts as an iron-binding protein and is strongly up-regulated in the brains of patients with AD [52]. In transgenic mice with AD these authors used double-immunofluorescence labelling with antibodies directed against $\mathrm{A} \beta$ and $\mathrm{LF}$, and found LF depositions localized to $\mathrm{A} \beta$ plaques and regions of amyloid angiopathy. Both the intensity and number of LF-positive depositions increased with age. The up-regulation of LF in the brains of both $\mathrm{AD}$ patients and transgenic mice with $\mathrm{AD}$ indicated an important protective role for LF in infected AD-brain tissue [53]. It is tempting to speculate that the high consumption of LF in AD could lead to reduced LF levels over time, particularly when $\mathrm{AD}$ is promoted by long-term chronic infection. Interestingly, BermejoPareja et al. [6] suggested that LF was downregulated in the saliva of AD patients like several other factors of systemic immunity.

\section{Concluding remarks}


If $\mathrm{LF}$ is a trigger of oral dysbiosis this makes it plausible that it could be a factor in the etiology or pathophysiology of AD. It is remarkable that the levels of LF are increased in the brains of $\mathrm{AD}$ patients, at least initially, and reduced in their whole saliva. It may be that the

220

221 long-term fight against chronic infection in the brain tends to reduce the level of LF. The latter scenario could aggravate brain infection. It is also possible that low levels of LF in the whole saliva of AD patients may affect the LF concentration in the brain since salivary LF is transferred into the brain via the sublingual route. In mice dietary LF supplementation prevented memory impairment and reduced $\mathrm{A} \beta$ generation, and post LF-administration for 3 months in $\mathrm{AD}$ patients alleviated the $\mathrm{AD}$ pathological cascade and cognitive decline by modulating the p-Akt/PTEN pathway. Furthermore, tablets containing LF and lactoperoxidase improved gingival inflammation and oral health-related quality of life in healthy adults suggesting LF supplements may be a plausible therapy for AD subjects, together with effective periodontitis prophylaxis and treatment to prevent systemic spread of periodontal bacteria.

Another intriguing aspect is that $P$. gingivalis, which is a keystone bacterium in periodontitis, and recently has been associated with $\mathrm{AD}$, has the ability to reduce LF levels through its gingipains. This could take place in the periodontal pocket, but could also occur in the brain of $\mathrm{AD}$ patients where both $P$. gingivalis and its gingipains have been detected. Noteworthy in this context is also the finding that $P$. gingivalis was the most powerful LFdegrading bacterium of several periodontal pathogens tested in vitro. It is plausible that $P$. gingivalis' effect on LF could be added to its wide capacity of immune suppression, acting both in the periodontal pocket and in the AD brain. There are also other proteins and peptides in saliva but their functions and interactions with the oral microbiome remain to be determined. Clearly, when the level of whole saliva is reduced, its composition is changed and this could promote dysbiosis and the risk of associated oral diseases such as caries, gingivitis, periodontitis and fungal infections, and possibly AD. For now, Carro et al. [3] and GonzálesSánchez et al. [4] have highlighted LF as an A $\beta$ biomarker of AD, and the authors of the current paper have suggested it to be a plausible trigger of oral dysbiosis. Further in vivo research on LF and its functions in causing dysbiosis of host mechanisms in the periodontal pocket and in the brain of $\mathrm{AD}$ patients is required to support our hypothesis.

\section{Acknowledgement}

No funding was achieved for this paper. 


\section{Compliance with ethical standards}

252

253

254

255

256

257

258

259

260

261

262

263

264

265

266

267

268

269

270

271

272

273

274

275

276

277

278

The authors have no relevant affiliations of financial involvement with any organization or entity with a financial interest in or financial conflict with the subject matter or materials discussed in the manuscript. This includes employment, consultancies, honoraria, stock ownership or options, expert testimony, grants or patents received or pending, or royalties.

\section{References}

1. Olsen I, Singhrao SK (2015) Can oral infection be a risk factor for Alzheimer's disease? J Oral Microbiol 7: 2914

2. Singhrao SK, Harding A (2020) Is Alzheimer's disease a polymicrobial host microbiome dysbiosis? Expert Rev Anti Infect Ther 18(4): 275-277

3. Carro E, Bartolomé F, Bermejo-Pareja F, Villarejo-Galende A, Molina JA, Ortiz P, Calero M, Rabano A, Cantero JL, Gorka Orive G (2017) Early diagnosis of mild cognitive impairment and Alzheimer's disease based on salivary lactoferrin. Alzheimer's Dement Diagnosis Assess Dis Monit 8: 131-138

4. González-Sánchez M, Bartolomé F, Antequera D, Puertas-Martín V, González P, GómezGrande A, Llamas-Velasco S, Herrero-San Martín A, Pérez-Martínez D, Villarejo-Galende A, Atienza M, Palomar-Bonet M, Cantero JL, Perry G, Orive G, Ibañez B, Bueno H, Fuster V, Carro E (2020) Decreased salivary lactoferrin levels are specific to Alzheimer's disease. EBioMedicine 57: 102834

5. Kell DB, Heyden EL, Pretorius E (2020) The biology of lactoferrin, an iron-binding protein that can help defend against viruses and bacteria. Front Immunol 11: 1221

6. Bermejo-Pareja F, del Ser T, Valenti M, de la Fuente M, Bartolome F, Carro E (2020) Salivary lactoferrin as biomarker for Alzheimer's disease: Brain-immunity interactions. Alzheimer's Dement 16: 1196-1204

7. Liu J-L, Fan Y-G, Yang Z-S, Wang Z-Y, Guo C (2018) Iron and Alzheimer's disease:

From pathogenesis to therapeutic implications. Front Neurosci 12: 632 
8. Olsen I (2020) Possible link between Porphyromonas gingivalis and amyloidosis in the pathogenesis of Alzheimer's and Parkinson's disease. Int J Pathol 1(1): 1-12

9. Olsen I, Singhrao SK (2020) Porphyromonas gingivalis infection may contribute to systemic and intracerebral amyloid-beta: implication for Alzheimer's disease onset. Expert Rev Anti Infect Ther 1-4

10. Farah R, Hardy H, Salame Z, Fares Y, Ojcius DM, Najwane Said Sadier NS (2018) Salivary biomarkers for the diagnosis and monitoring of neurological diseases. Biomed J 41(2): 63-87

11. Rogers J, Luber-Narod J, Styren SD, Civin WH (1988) Expression of immune systemassociated antigens by cells of the human central nervous system: relationship to the pathology of Alzheimer's disease. Neurobiol Aging 9: 339-349

12. McGeer PL, Akiyama H, Itagaki S, McGeer EG (1989) Immune system response in Alzheimer's disease. Can J Neurol Sci 16(4 Suppl): 516-527

13. Jevtic S, Sengar AS, Salter MW, McLaurin J (2017) The role of the immune system in Alzheimer disease: Etiology and treatment. Ageing Res Rev 40: 84-94

14. Olsen I, Singhrao SK (2019) Is there a link between genetic defects in the complement cascade and Porphyromonas gingivalis in Alzheimer's disease? J Oral Microbiol 12(1): 167648

15. Sochocka M, Zwolińska K, Leszek J (2017) The infectious etiology of Alzheimer's disease. Curr Neuropharmacol 15(7): 996-1009

16. Lynge Pedersen AM, Belstrøm D (2019) The role of natural salivary defences in maintaining a healthy oral microbiota. J Dent 80: S3-S12

17. Lamont RJ, Hajishengallis G (2015) Polymicrobial synergy and dysbiosis in inflammatory disease. Trends Mol Med 21(3): 172-183

18. Berlutti F, Pilloni A, Pietropaoli M, Polimeni A, Valenti P (2011) Lactoferrin and oral diseases: current status and perspective in periodontitis. Ann Stomatol (Roma) 2(3-4): 10-18

19. Holmer J, Aho V, Eriksdotter M, Paulin L, Pietiäinen M, Auvinen P, Schultzberg M, Pussinen PJ, Buhlin K (2020) The subgingival microbiota of people with cognitive dysfunction. J Oral Microbiol 12: submitted 
20. Mizuhashi F, Koide K, Toya S, Takahashi M, Mizuhashi R, Shimomura H (2015) Levels of the antimicrobial proteins lactoferrin and chromogranin in the saliva of individuals with oral dryness. J Prosthet Dent 113(1): 35-38

21. Pretorius L, Kell DB, Pretorius E (2018) Iron dysregulation and dormant microbes as causative agents for impaired blood rheology and pathological clotting in Alzheimer's type dementia. Front Neurosci 12: 851

\section{Pretorius E, Bester J, Kell DB (2016) A bacterial component to Alzheimer's-type} dementia seen via a systemic biology approach that links iron dysregulation and inflammagen shedding to disease. J Alzheimers Dis 53(4): 1237-1256

23. Lipinski B, Pretorius E (2013) The role of iron-induced fibrin in the pathogenesis of Alzheimer's disease and the protective role of magnesium. Front Hum Neurosci 7: 735

24. Wakabayashi H, Kondo I, Kobayashi T, Yamauchi K, Toida T, Iwatsuki K, Yoshie H (2020) Periodontitis, periodontopathic bacteria and lactoferrin. Biometals 23(3): 419-424

25.Wakabayashi H, Yamauchi K, Kobayashi T, Yaeshima T, Iwatsuki K, Yoshie H (2009) Inhibitory effects of lactoferrin on growth and biofilm formation of Porphyromonas gingivalis and Prevotella intermedia. Antimicrob Agents Chemother 53(8): 3308-3316

26. Glimvall P, Wickström C, Jansson H (2012) Elevated levels of salivary lactoferrin, a marker for chronic periodontitis? J Periodontal Res 47(5): 655-660

27. Dashper SG, Pan Y, Veith PD, Che Y-Y, Toh ECY, Liu SW, Cross KJ, Reynolds EC (2012) Lactoferrin inhibits Porphyromonas gingivalis proteinases and has sustained biofilm inhibitory activity. Antimicrob Agents Chemother 56(3): 1548-1556

28. Socransky SS, Haffajee AD, Cugini MA, Smith C, Kent RL Jr (1998) Microbial complexes in subgingival plaque. J Clin Periodontol 25(2): 134-144

29. Hajishengallis G, Darveau RP, Curtis MA (2012) The Keystone-Pathogen Hypothesis. Nat Rev Microbiol 10: 717-725

30. Darveau RP, Hajishengallis G, Curtis MA (2012) Porphyromonas gingivalis as a potential community activist for disease. J Dent Res 91: 816-820.

31. de Lillo A, Teanpaisan R, Fierro JF, Douglas CW (1996) Binding and degradation of lactoferrin by Porphyromonas gingivalis, Prevotella intermedia and Prevotella nigrescens. FEMS Immunol Med Microbiol 14(2-3): 135-143 
32. Alugupalli KR, Kalfas S (1996) Degradation of lactoferrin by periodontitis-associated bacteria. FEMS Microbiol Lett 145(2): 209-214

33. Nunes JM, Fillis T, Page MJ, Venter C, Launcry O, Kell DB, Windberger U, Pretorius E (2020) Gingipain R1 and lipopolysaccharide from Porphyromonas gingivalis have major effects on blood clot morphology and mechanics. Front Immunol 11: 1551

34. Nakano M, Yoshida A, Wakabayashi H, Tanaka M, Yamauchi K, Abe F, Masuda Y (2019) Effect of tablets containing lactoferrin and lactoperoxidase on gingival health in adults: A randomized, double-blind, placebo controlled clinical trial. J Periodontal Res 54(6):702-708

35. Itzhaki RF, Lathe R, Balin BJ, Ball MJ, Bearer EL, Braak H, Bullido MJ, Carter C, Clerici M, Cosby SL, Tredici KD, Field H, Fulop T, Grassi C, Griffin WST, Haas J, Hudson AP, Kamer AR, Kell DB, Licastro F, Letenneur L, Lövheim H, Mancuso R, Miklossy J, Otth C, Palamara AT, Perry G, Preston C, Pretorius E, Strandberg T, Tabet N, Taylor-Robinson S-D, Whittum-Hudson JA (2016) Microbes and Alzheimer's disease. J Alzheimers Dis 51(4): 979-984

36. Ilievski V, Zuchowska PK, Green SJ, Toth PT, Ragozzino ME, Le K, Aljewari HW, O'Brien-Simpson NM, Reynolds EC, Watanabe K (2018) Chronic oral application of a periodontal pathogen results in brain inflammation, neurodegeneration and amyloid beta production in wild type mice. PLoS One 13(10): e0204941

37. Dominy SS, Lynch C, Ermini F, Benedyk M, Marczyk A, Konradi A, Nguyen M, Haditsch U, Raha D, Griffin C, Holsinger LJ, Arastu-Kapur S, Kaba S, Lee A, Ryder MI, Potempa B, Mydel P, Hellvard A, Adamowicz K, Hasturk H, Walker GD, Reynolds EC, Faull RLM, Curtis MA, Dragunow M, Potempa J (2019) Porphyromonas gingivalis in Alzheimer's disease brains: evidence for disease causation and treatment with smallmolecule inhibitors. Sci Adv 5(1): eaau3333

38. Olsen I, Singhrao SK (2019) Poor oral health and its neurological consequences: Mechanisms of Porphyromonas gingivalis involvement in cognitive dysfunction. Curr Oral Health Rep 6: 120-129

39. Singhrao SK, Olsen I (2019) Assessing the role of Porphyromonas gingivalis in periodontitis to determine a causative relationship with Alzheimer's disease. J Oral Microbiol 11: 1563405 
40. Olsen I, Singhrao SK (2020) Interaction between genetic factors, Porphyromonas gingivalis and microglia to promote Alzheimer's disease. J Oral Microbiol 12: 1820834 41. Sparks Stein P, Steffen MJ, Smith C, Jicha G, Ebersole JL, Abner E, Dawson D 3rd (2012) Serum antibodies to periodontal pathogens are a risk factor for Alzheimer's disease. Alzheimers Dement 8: 196-203

42.Tzeng N-S, Chung C-H, Yeh C-B, Huang R-Y, Yuh D-Y, Huang S-Y, Lu R-B, Chang H-A, Kao Y-C, Chiang W-S, Chou Y-C, Chien W-C (2016) Are chronic periodontitis and gingivitis associated with dementia? A nationwide, retrospective, matched-cohort study in Taiwan. Neuroepidemiology 47: 82-93

43. Chen C-K, Wu Y-T, Chang Y-C (2017) Association between chronic periodontitis and the risk of Alzheimer's disease: a retrospective, population-based, matched-cohort study. Alzheimers Res Ther 9: 56

44. Tomás I, Diz P, Tobías A, Scully C, Donos N (2012) Periodontal health status and bacteraemia from daily oral activities: systematic review/meta-analysis. J Clin Periodontol 39: $213-228$

45. Bahrani-Mougeot FK, Paster BJ, Coleman S, Ashar J, Barbuto S, Lockhart PB (2008) Diverse and novel oral bacterial species in blood following dental procedures. J Clin Microbiol 46(2): 2129-2132

46. Poole S, Singhrao SK, Kesavalu L, Curtis MA, Crean S (2013) Determining the presence of periodontopathic virulence factors in short-term postmortem Alzheimer's disease brain tissue. J Alzheimers Dis 36(4): 665-677

47. Poole S, Singhrao SK, Chukkapalli S, Rivera M, Velsko I, Kesavalu L, Crean S (2015) Active invasion of Porphyromonas gingivalis and infection-induced complement activation of ApoE $^{-/-}$mice brains. J Alzheimers Dis 43(1): 67-80

48. Siddiqui H, Eribe ERK, Singhrao SK, Olsen I (2019) High throughput sequencing detects gingivitis and periodontal oral bacteria in Alzheimer's disease autopsy brains. Neuro Res $1(1): 3$

49. Hayashi T, To M, Saruta J, Sato C, Yamamoto Y, Kondo Y, Shimizu T, Kamata Y, Tsukinoki K (2017) Salivary lactoferrin is transferred into the brain via the sublingual route. Biosci Biotechnol Biochem 81(7): 1300-1304 
399

400

401

402

403

404

405

406

407

408

409

410

50. Mohamed WA, Salama RM, Schaalan MF (2019) A pilot study on the effect of lactoferrin on Alzheimer's disease pathological sequelae: Impact of the p-Akt/PTEN pathway. Biomed Pharmacother 111: 714-723

51. Lepanto MS, Rosa L, Paesano R, Valenti P, Cutone A (2019) Lactoferrin in aseptic and septic inflammation. Molecules 24(7): 1323

52. Wang L, Sato H, Zhao S, Tooyama I (2010) Deposition of lactoferrin in fibrillar-type senile plaques in the brains of transgenic mouse models of Alzheimer's disease. Neurosci Lett 481(3): 164-167

53. Abdelhamid M, Jung C-G, Zhou C, Abdullah M, Nakano M, Wakabayashi H, Abe F, Michikawa M (2020) Dietary lactoferrin supplementation prevents memory impairment and reduces amyloid- $\beta$ generation in J20 mice. J Alzheimers Dis 74(1): 245-259

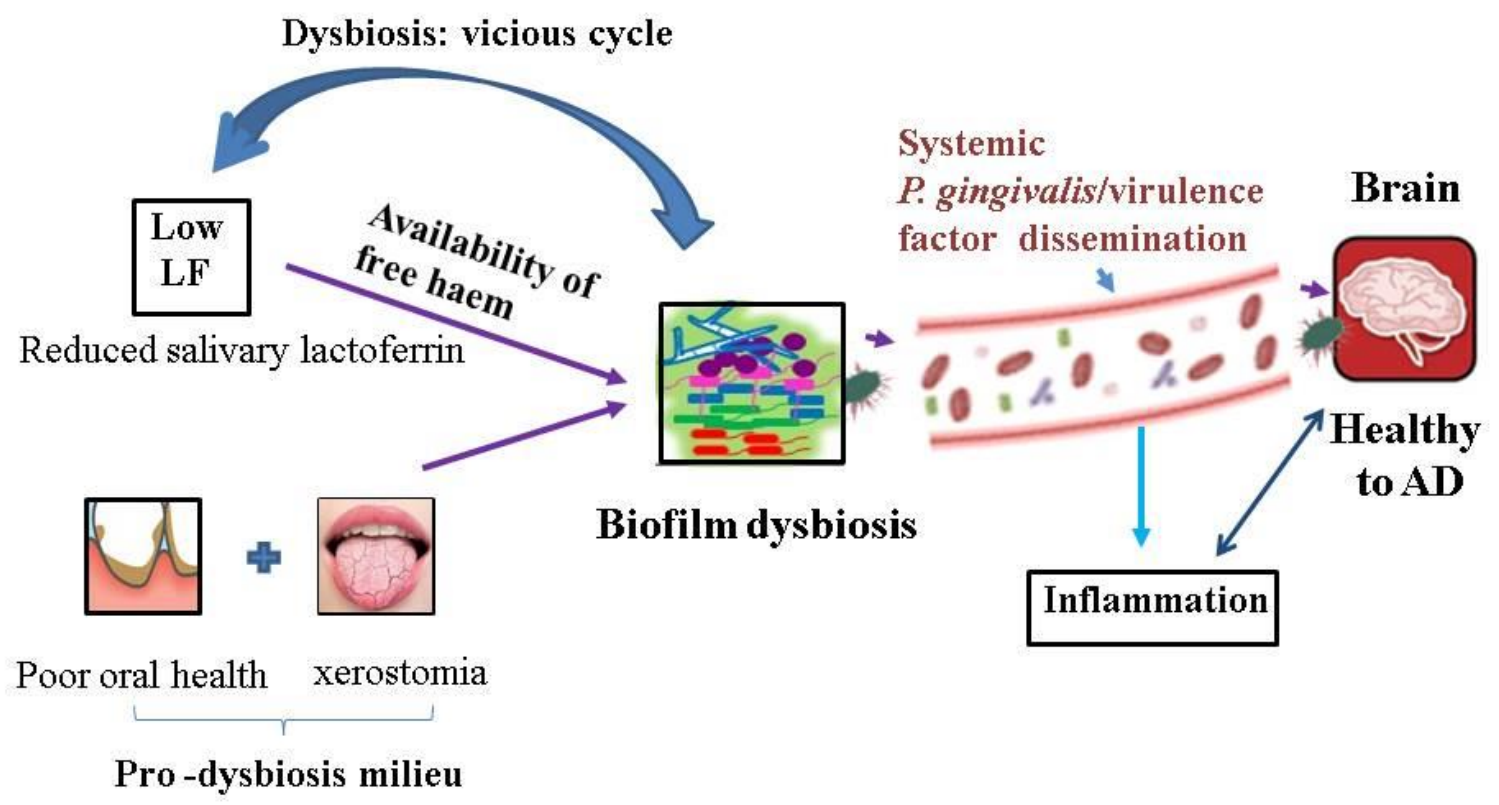

412 Figure 1. Schematic to show how reduced levels of salivary lactoferrin (LF) may be a 413 plausible trigger of oral biofilm dysbiosis. Oral dysbiosis has largely been seen as a result of 414 inadequate oral hygiene and xerostomia in elderly subjects. Once the LF level begins to 
415 decrease, this becomes a vicious cycle for sustained dysbiosis. From here $P$. gingivalis can

416 spread, via bacteremia, to disparate body organs, for example the brain. This destabilize the 417 immune balance, and inflammatory disease such as AD (Alzheimers'disease) develops.

418

419

420

421

422

423

424

425

426

427 
Table 1. Physiological properties of lactoferrin (adopted from [5])

\begin{tabular}{|c|c|}
\hline Physiological actions & Mechanisms \\
\hline Iron-binding protein & Iron absorption, transport and sequestration \\
\hline \multirow[t]{5}{*}{ Host defence } & Activities against pathogens: antibacterial, antifungal, antiparasitic, antiviral \\
\hline & Anti-inflammatory and alarming \\
\hline & Anti-endotoxin \\
\hline & Anticancer \\
\hline & Inhibition of prion accumulation \\
\hline \multirow[t]{5}{*}{ Host activities } & Brain development and neuroprotection: alleviating psychological stress \\
\hline & Bone formation \\
\hline & Gastrointestinal development \\
\hline & Immune actions (innate and adaptive): enhancer and modulator \\
\hline & Wound healing \\
\hline \multirow[t]{8}{*}{ Metabolic } & Adipocytes differentiation \\
\hline & Antioxidant: inhibiting lipid peroxidation \\
\hline & Association with other proteins: osteopontin and others \\
\hline & Decreasing vasoconstriction \\
\hline & Enzymatic activities \\
\hline & Glucose regulation (decreasing hyperglycemia) \\
\hline & Gut microbiota modulation \\
\hline & Transcriptional regulator \\
\hline \multirow[t]{3}{*}{ Miscellaneous } & Compounds or metabolites carrier (mainly into brain) \\
\hline & Vaccine adjuvant \\
\hline & Possible sAD biomarker \\
\hline
\end{tabular}


